p-ISSN:2599-1914

Volume 1 Nomor 3 Tahun 2018

e-ISSN:2599-1132

\title{
UPAYA MENINGKATKAN KREATIVITAS SISWA MELALUI MODEL PROJECT BASED LEARNING
}

\author{
Fitri Agustina Lubis \\ Pendidikan Biologi, FKIP Universitas Muhammadiyah Tapanui Selatan \\ fitri.agustina@um-tapsel.ac.id
}

DOI : 10.31604/ptk.v1i3.192-201

\begin{abstract}
This research aims to improve the management of creativity and learning biology learning model through the application of Project Based Learning (the execution) on the subject of environmental pollution in the class X MIA-1 SMA Negeri 1 Sipirok TP 2017/2018. This type of research this is a class action research (PTK) using two cycles of learning. Data collection techniques used are tests and observations with tool test of creativity and learning management of biological observation sheets. Based on the results of research conducted, the test results obtained in cycle I, with a total value of 2299 , the value of the average number of students who complete 71.84 as many as 9 people $(71.87 \%)$ and cycle II obtained total value of 2995 with average number of 93.59 students who complete 30 people $(93.75 \%)$ so that the cycle of I to II an increase in cycle $7(21.88 \%)$. As for the observations against the management of the biological cycle of learning, I obtained an average percentage of $70 \%$, and on Siculus II becomes $91 \%$. Thus, from cycle to cycle I II occur an increase of $21 \%$ from qulification simply be good criteria. The study was finalized in cycle II because the indicators of success have been achieved and meets the criteria of so that the conclusions of this research is that learning through Project Based Learning (the execution), it can increase creativity and learning areas of biology on the subject of environmental pollution in the class $\mathrm{X}$ MIA-1 SMA Negeri 1 Sipirok TP 2017/2018.
\end{abstract}

Keywords: Creativity, Project Based Learning (PjBL), Environmental Pollution.

\begin{abstract}
Abstrak
Penelitian ini bertujuan untuk meningkatkan kreativitas dan pengelolaan pembelajaran biologi melalui penerapan model pembelajaran Project Based Learning (PjBL) pada pokok bahasan pencemaran lingkungan di kelas X MIA-1 SMA Negeri 1 Sipirok TP 2017/2018. Jenis penelitian ini adalah penelitian tindakan kelas (PTK) dengan menggunakan dua siklus pembelajaran. Teknik pengumpulan data yang digunakan adalah tes dan observasi dengan alat pengumpulan data berupa lembar tes kreativitas dan lembar observasi pengelolaan pembelajaran biologi. Berdasarkan hasil penelitian yang dilakukan, diperoleh hasil tes pada siklus I dengan jumlah nilai 2299, nilai ratarata 71,84 jumlah siswa yang tuntas sebanyak 9 orang $(71,87 \%)$ dan pada siklus II diperoleh jumlah nilai 2995 dengan nilai rata-rata 93,59 jumlah siswa yang tuntas 30 orang $(93,75 \%)$ sehingga dari siklus I ke siklus II terjadi peningkatan 7 orang $(21,88 \%)$. Adapun hasil observasi terhadap pengelolaan pembelajaran biologi dari siklus I diperoleh persentase rata-rata $70 \%$ dan pada sikulus II menjadi $91 \%$. Dengan demikian, dari siklus I ke siklus II terjadi peningkatan sebesar $21 \%$ dari kulaifikasi cukup menjadi
\end{abstract}


PeTeKa (Jurnal Penelitian Tindakan Kelas dan Pengembangan Pembelajaran)

Vol 1 No 3 Tahun 2018 Hal 192-201

kriteria baik. Penelitian ini disudahi pada siklus II karena indikator keberhasilan telah tercapai dan memenuhi kriteria ketuntasan sehingga kesimpulan dari penelitian ini adalah bahwa melalui model pembelajaran Project Based Learning (PjBL), ternyata dapat meningkatkan kreativitas dan pegelolaan pembelajaran biologi pada pokok bahasan pencemaran lingkungan di kelas $\mathrm{X}$ MIA-1 SMA Negeri 1 Sipirok TP $2017 / 2018$.

Kata Kunci: Kreativitas, Project Based Learning (PjBL), Pencemaran Lingkungan.

\section{PENDAHULUAN}

Pendidikan pada hakekatnya suatu usaha untuk mengembangkan kemampuan secara aktif, pengendalian diri, kepribadian, kecerdasan, meningkatkan kreativitas seseorang dan juga keterampilan yang dibutuhkan oleh lingkungan mereka. Fatmawati (2011) menyatakan rendahnya pengembangan kreativitas disebabkan pembelajaran yang dilatihkan adalah pengetahuan, ingatan/hafalan, kemampuan berpikir logis atau berpikir konvergen yaitu kemampuan menemukan satu jawaban yang paling tepat terhadap masalah yang diberikan berdasarkan informasi yang tersedia.

Hakim (2015), guru sebagai komponen yang utama dalam dunia pendidikan dituntut untuk mampu mengimbangi bahkan melampaui perkembangan ilmu pengetahuan dan teknologi yang berkembang dalam masyarakat. Guru di sekolah diharapkan mampu menghasilkan peserta didik yang dapat memiliki kompetensi tinggi dan siap menghadapi tantangan hidup dengan penuh keyakinan dan percaya diri yang tinggi. Pemilihan strategi pembelajaran yang tepat dapat memotivasi mahasiswa untuk belajar dan membangun pengetahuan mereka sendiri Untuk kedepan sekolah harus mampu menciptakan sumber daya manusia yang berkualitas, baik dalam keilmuan (akademis) maupun secara sifat mental.
Hasil wawancara dengan Ibu Nurliana Rambe, S.Pd mengatakan bahwa model pembelajaran yang digunakan sudah bervariasi, mulai dari pembelajaran mandiri, kelompok sampai kepada metode penugasan., akibatnya siswa kurang diberi kesempatan untuk memikirkan dan mengembangkan potensi-potensi yang dimiliki dan akhirnya berdampak pada rendahnya kreativitas belajar siswa.

Untuk meningkatkan kreativitas siswa dalam pembelajaran biologi, banyak hal yang yang dilakukan oleh guru, diantaranya mencoba suatu model pembelajaran yang baru dengan dengan menggali keterampilan analisis siswa secara optimal sehingga siswa dapat menghubungkan dan menyimpulkan konsep materi dengan fenomena di lingkungan sekitar. Model pembelajaran yang diharapkan tepat dan sesuai untuk mengarah pada hal-hal tersebut yaitu Project Based Learning (Model Pembelajaran Berbasis Proyek).

Fatmawati (2011), siswa melalui proses desain proyek bukan hanya mengubah metode pengajaran dan lingkungan belajar tetapi juga mengadopsi metode baru dalam penilaian, seperti penilaian portofolio. Pengetahuan yang diperoleh menjadi lebih berarti dan kegiatan pembelajaran menjadi lebih menarik, karena pengetahuan itu bermanfaat baginya untuk lebih mengapresiasi lingkungan.

Penelitian terdahulu telah dilakukan oleh Insyasiska, dkk (2015) 
Fitri Agustina Lubis. Upaya Meningkatkan Kreativitas Siswa Melalui ...

dengan judul "Pengaruh Project Based Learning Terhadap Motivasi Belajar, Kreativitas, Kemampuan Berpikir Kritis dan Kemampuan Kognitif Siswa Pada Pembelajaran Biologi. Hasil penelitian menunjukkan bahwa project based learning dapat meningkatkan kreativitas siswa sebesar $31,1 \%$ dari siklus I ke siklus II. Pembelajaran berbasis proyek juga menghasilkan ide-ide kreatif yang kemudian diwujudkan dalam suatu produk.

\section{METODE}

Jenis penelitian ini adalah Penelitian Tindakan Kelas (PTK). Menurut Sani (2012) penelitian tindakan kelas (classroom action) merupakan suatu penelitian yang diaplikasikan dalam kegiatan belajar mengajar di kelas dengan maksud memperbaiki proses belajar. Dalam penelitian ini, proses yang diperbaiki adalah model pembelajaran yang diterapkan di kelas sehingga mampu meningkatkan kreativitas belajar siswa.

Penelitian ini dilaksanakan di SMA Negeri 1 Sipirok yang beralamat di Jl. Simangambat Kecamatan Sipirok Kabupaten Tapanuli Selatan, Sumatera Utara. Waktu penelitian ini dilaksanakan terhitung sejak bulan April sampai dengan Juli 2018. Subjek dalam penelitian ini adalah siswa kelas $X$ MIA-1 di SMA Negeri 1 Sipirok yang berjumlah 32 orang dengan jumlah laki-laki 12 orang dan perempuan 20 orang.Objek penelitian ini adalah kreativitas dan pengelolaan pembelajaran biologi pada pokok bahasan pencemaran Lingkungan di kelas X MIA-1 SMA Negeri 1 Sipirok Tahun Pelajaran 2017/2018. prosedur penelitian tindakan kelas teridiri dari beberapa siklus dan setiap siklus terdiri dari 4 tahap yaitu mulai dari tahap perencanaan tindakan perbaikan, pelaksanaan tindakan, observasi dan refleksi.

\section{HASIL DAN PEMBAHASAN}

Hasil penelitian disajikan berdasarkan urutan kronologis sebelum dan sesudah diberi tindakan. Peneliti terlebih dahulu mendeskripsikan kondisi awal sebelum diberi tindakan (pra-siklus) lalu membandingkannya dengan hasil penelitian setelah diberi tindakan yang disebut sebagai siklus penelitian tindakan kelas. Penelitian ini terdiri dari 2 siklus penelitian dengan tahapan masing-masing siklus dimulai dari tahap perencanaa, pelaksanaan, pengamatan (observasi) dan refleksi.

\section{Kondisi Awal (Prasiklus)}

Kondisi awal penelitian diamati ketika peneliti mengunjungi sekolah SMA Negeri 1 Sipirok yang beralamat di Jalan Simangambat Kecamatan Sipirok Kabupaten Tapanuli Selatan pada tanggal 27 November 2018 kemudian melakukan wawancara dengan Ibu Nurliana Rambe, S.Pd selaku guru mata pelajaran biologi dan diperoleh informasi bahwa model pembelajaran yang digunakan guru sudah bervariasi, mulai dari pembelajaran mandiri, kelompok sampai kepada metode penugasan. 
PeTeKa (Jurnal Penelitian Tindakan Kelas dan Pengembangan Pembelajaran)

Vol 1 No 3 Tahun 2018 Hal 192-201

Tabel 1: Rekapitulasi Data Hasil Tes Berdasarkan Indikator Kreativitas Prasiklus

\begin{tabular}{|c|c|c|c|}
\hline No & Indikator Kreativitas & Hasil Tes & Keterangan \\
\hline 1. & Fleksibilitas & $67,08 \%$ & Tidak tuntas \\
\hline 2. & Originalitas & $67,91 \%$ & Tidak tuntas \\
\hline 3. & Elaborasi & $71,11 \%$ & Tidak tuntas \\
\hline \multirow[t]{3}{*}{4.} & Fluency & $59 \%$ & Tidak tuntas \\
\hline & Jumlah & 265,10 & \\
\hline & Rata-rata & $66,27 \%$ & \\
\hline
\end{tabular}

Hal ini dapat dibuktikan dengan nilai hasil tes kreativitas yang dilakukan pada saat prapenelitian di kelas X MIA1 SMA Negeri 1 Sipirok, dari 32 siswa yang diberi tes, ternyata hanya 13 orang $(40,62 \%)$ siswa yang mencapai ketuntasan dengan KKM 75, sementara sisanya sebanyak $19(59,34 \%)$ orang dinyatakan tidak tuntas. Adapun nilai rata-rata kelas yaitu 40,62\% (kualifikasi rendah). Dari data tersebut kemudian di analisa berdasarkan indikator kreativitas yang dinilai.

Dari data dapat disimpulkan bahwa kreativitas belajar siswa masih rendah. Untuk itu, peneliti akan berkolaborasi dengan guru mata pelajaran biologi untuk dapat meningkatkan kreativitas belajar siswa pada pertemuan selanjutnya dengan menerapkan model pembelajaran PjBL.

\section{Hasil Penelitian Siklus I}

Soal dibagikan kepada 32 siswa di kelas X MIA-1 SMA Negeri 1 pada tanggal 28 April 2018. Hasil tes dalam bentuk lembar jawaban siswa kemudian dikoreksi dan dinillai lalu di anlisa dengan mencari nilai rata-rata dalam setiap indikator kreativitas sebagaimana terlihat pada tabel 2.

Pengamatan

(Observasi) pembelajaran dilaksanakan, maka pengelolaan pembelajaran biologi diamati sesuai dengan indikatorindikatornya yang dilakukan oleh observer/observator. Dalam hal ini, peneliti berkolaborasi dengan teman sejawat untuk mengamati setiap gerakgerik peneliti dalam menerapkan model pembelajaran $\mathrm{PjBL}$ pada pencemaran lingkungan di kelas X MIA-1 SMA Negeri 1 Sipirok tahun pelajaran 20172018 sebagaimana terlihat pada tabel 3.

Tabel 2: Rekapitulasi Data Hasil Tes Berdasarkan Indikator Kreativitas Siklus I

\begin{tabular}{|c|c|c|c|}
\hline No & Indikator Kreativitas & Rata-rata (\%) & Kriteria \\
\hline 1. & Fleksibilitas & 72.30 & Cukup \\
\hline 2. & Originalitas & 71.15 & Cukup \\
\hline 3. & Elaborasi & 71.60 & Cukup \\
\hline \multirow[t]{3}{*}{4.} & Fluency & 72.26 & Cukup \\
\hline & Jumlah & 287.31 & \\
\hline & Rata-rata & 71.87 & \\
\hline
\end{tabular}


Fitri Agustina Lubis. Upaya Meningkatkan Kreativitas Siswa Melalui ...

Tabel 3: Hasil Observasi Pengelolaan Pembelajaran Siklus I

\begin{tabular}{|c|c|c|c|c|c|}
\hline \multirow{2}{*}{ Aspek yang Diamati } & \multicolumn{4}{|c|}{ Skala } & \multirow[b]{2}{*}{ Skor } \\
\hline & 4 & 3 & 2 & 1 & \\
\hline A. Pendahuluan & & & & & \\
\hline 1. Melakukan apersepsi & & $\sqrt{ }$ & & & 3,00 \\
\hline 2. Memotivasi siswa untuk mengikuti pelajaran & & $\sqrt{ }$ & & & 3,00 \\
\hline 3. Menyampaikan tujuan pembelajaran & & $\sqrt{ }$ & & & 3,00 \\
\hline B. Kegiatan Inti & & & & & \\
\hline 1. Menguasai bahan & & $\sqrt{ }$ & & & 3,00 \\
\hline 2. Penyajian jelas & & $\sqrt{ }$ & & & 3,00 \\
\hline 3. Mempersiapkan materi pelajaran dengan sistematis & & $\sqrt{ }$ & & & 3,00 \\
\hline $\begin{array}{l}\text { 4. Melaksanakan kegiatan pembelajaran yang sesuai } \\
\text { dengan pembelajaran dalam urutan dan arah yang } \\
\text { jelas }\end{array}$ & & $\sqrt{ }$ & & & 3,00 \\
\hline 5. Upaya menertibkan siswa & & & $\sqrt{ }$ & & 2,00 \\
\hline $\begin{array}{l}\text { 6. Memberikan kesempatan kepada siswa untuk } \\
\text { mengungkapkan pendapatnya }\end{array}$ & & $\sqrt{ }$ & & & 3,00 \\
\hline 7. Mengungkapkan pertanyaan dengan jelas dan singkat & & $\sqrt{ }$ & & & 3,00 \\
\hline 8. Merespon jawaban siswa & & $\sqrt{ }$ & & & 3,00 \\
\hline 9. Memuji siswa yang berprestasi & & & $\sqrt{ }$ & & 2,00 \\
\hline 10. Memberikan dan menilai hasil pelajaran siswa & & $\sqrt{ }$ & & & 3,00 \\
\hline 11. Memotivasi siswa agar lebih giat belajar & & $\sqrt{ }$ & & & 3,00 \\
\hline C. Kegiatan Penutup & & & & & \\
\hline 1. Merangkum isi pelajaran & & $\sqrt{ }$ & & & 3,00 \\
\hline 2. Memberi tugas & & $\sqrt{ }$ & & & 3,00 \\
\hline D. Suasana Belajar & & & & & \\
\hline 1. Siswa antusias & & & $\sqrt{ }$ & & 2,00 \\
\hline 2. Guru antusias & & $\sqrt{ }$ & & & 3,00 \\
\hline 3. Waktu sesuai alokasi & & $\sqrt{ }$ & & & 3,00 \\
\hline 4. KBM sesuai dengan skenario RPP & & & $\sqrt{ }$ & & 2,00 \\
\hline Jumlah & & & & & 56 \\
\hline Rata-rata & & & & & 2,8 \\
\hline Persentase & & & & & $70 \%$ \\
\hline
\end{tabular}

Penelitian merefleksi kreativitas belajar siswa melalui tes yang dilaksanakan di kelas sesudah melaksanakan materi ajar dengan model pembelajaran Project Based Learning dan dari hasil yang diperoleh, penelitian tindakan kelas ini masih berlanjut karena kreativitas siswa pada pelajaran biologi pokok pembahasan pencemaran lingkungan yang ditandai dengan tingkat ketuntasan tes belum mencapai minimal 75 belum tercapai. Adapaun hasil refleksi pada siklus I dapat dilihat pada tabel 4. 
PeTeKa (Jurnal Penelitian Tindakan Kelas dan Pengembangan Pembelajaran)

Vol 1 No 3 Tahun 2018 Hal 192-201

Tabel 4: Hasil Refleksi Terhadap Pelaksanaan Siklus I

\begin{tabular}{|c|c|c|c|c|}
\hline No & $\begin{array}{c}\text { Topik yang } \\
\text { dibahas }\end{array}$ & $\begin{array}{c}\text { Hambatan } \\
\text { yang ditemui }\end{array}$ & $\begin{array}{c}\text { Dugaan penyebab } \\
\text { hambatan }\end{array}$ & Solusi yang dipilih \\
\hline 1 & $\begin{array}{l}\text { Evaluasi } \\
\text { hasil tes }\end{array}$ & $\begin{array}{l}\text { Persentase } \\
\text { ketuntasan } \\
\text { belum tercapai }\end{array}$ & $\begin{array}{l}\text { Siswa yang aktif } \\
\text { dalam pembelajaran } \\
\text { masih didominasi oleh } \\
\text { siswa yang pandai }\end{array}$ & \begin{tabular}{lr}
\multicolumn{2}{l}{ Lebih memperhatikan } \\
siswa yang & kurang \\
pandai agar & terlibat \\
dalam & proses \\
pembelajaran &
\end{tabular} \\
\hline 2 & $\begin{array}{l}\text { Mengerjakan } \\
\text { tugas }\end{array}$ & $\begin{array}{l}\text { Hanya siswa } \\
\text { yang } \\
\text { berkamumpua } \\
\mathrm{n} \text { tinggi yang } \\
\text { mengerjakan } \\
\text { tugas dengan } \\
\text { baik }\end{array}$ & $\begin{array}{l}\text { Masih banyak siswa } \\
\text { yang kurang mengerti } \\
\text { mengenai materi yang } \\
\text { diajarkan }\end{array}$ & $\begin{array}{l}\text { Memotivasi siswa } \\
\text { agar mengerjakan } \\
\text { tugas } \\
\text { menjelaskan materi } \\
\text { dengan sederhana } \\
\text { agar lebuh mudah } \\
\text { dimengerti siswa }\end{array}$ \\
\hline 3 & $\begin{array}{l}\text { Interaksi } \\
\text { dengan } \\
\text { teman dalam } \\
\text { diskusi } \\
\text { kelompok }\end{array}$ & $\begin{array}{l}\text { Masih banyak } \\
\text { siswa yang } \\
\text { tidakmelakuka } \\
\text { n aktivitas ini }\end{array}$ & $\begin{array}{lr}\text { Siswa kurang } \\
\text { memahami cara } \\
\text { menggunakan } & \text { LKS }\end{array}$ & $\begin{array}{l}\text { Mengarahkan } \\
\text { penggunaannya dan } \\
\text { menjelaskan kepada } \\
\text { siswa tentang apa } \\
\text { yang akan dikerjakan }\end{array}$ \\
\hline 4 & $\begin{array}{l}\text { Menyampaik } \\
\text { an petanyaan } \\
\text { atau } \\
\text { pernyataan }\end{array}$ & $\begin{array}{l}\text { Pada } \\
\text { umumnya } \\
\text { siswa } \\
\text { tidakmau } \\
\text { melakukannya }\end{array}$ & $\begin{array}{l}\text { Para siswa takut jika } \\
\text { salah dan malu } \\
\text { mengungkapakan } \\
\text { pertanyaan/pernyataan } \\
\text { nya }\end{array}$ & $\begin{array}{l}\text { Mengarahkan mereka } \\
\text { agar mau bertanya } \\
\text { supaya materi yang } \\
\text { dipelajari dapat } \\
\text { dikuasai dengan baik }\end{array}$ \\
\hline
\end{tabular}

\section{Hasil Penelitian Siklus II}

Evaluasi dengan membagi soal berbentuk essay test berjumlah 10 butir untuk menilai kreativitas siswa dalam menjawab soal-soal pencemaran lingkungan. Soal ini dibagikan kepada 32 siswa di kelas X MIA-1 SMA Negeri
1 tahun pelajaran 2017-2018 pada tanggal 285 Mei 2018. Hasil tes dalam bentuk lembar jawaban siswa kemudian dikoreksi dan dinillai lalu di anlisa dengan mencari nilai rata-rata dalam setiap indikator kreativitas sebagaimana terlihat pada tabel 5 .

Tabel 5: Rekapitulasi Data Hasil Tes Berdasarkan Indikator Kreativitas Siklus II

\begin{tabular}{|c|c|c|c|}
\hline No & Indikator Kreativitas & Rata-rata & Kriteria \\
\hline 1. & Fleksibilitas & 93,02 & Baik \\
\hline 2. & Originalitas & 92,92 & Baik \\
\hline 3. & Elaborasi & 95,15 & Baik \\
\hline \multirow[t]{3}{*}{4.} & Fluency & 93,91 & Tuntas \\
\hline & Jumlah & 375 & Baik \\
\hline & Rata-rata & 93,75 & Baik \\
\hline
\end{tabular}


Fitri Agustina Lubis. Upaya Meningkatkan Kreativitas Siswa Melalui ...

Pengamatan (Observasi) pembelajaran siklus II dilaksanakan, maka pengelolaan pembelajaran biologi diamati sesuai dengan indikatorindikatornya yang dilakukan oleh observer/observator. Hasil pengelolaan pembelajaran biologi dalam menerapkan model pembelajaran Project based learning pada konsep hukm newton siswa kelas X MIA-1 SMA Negeri 1 Sipirok. Tahun pelajaran 2017-2018 pada siklus II dapat dilihat pada tabel 6 .

Tabel 6: Hasil Observasi Pengelolaan Pembelajaran Biologi Siklus II

\begin{tabular}{|c|c|c|c|c|}
\hline \multirow{2}{*}{ Aspek yang Diamati } & \multicolumn{3}{|c|}{ Skala } & \multirow[t]{2}{*}{ Skor } \\
\hline & 4 & 32 & 1 & \\
\hline A. Pendahuluan & & & & \\
\hline 1. Melakukan apersepsi & $\sqrt{ }$ & & & 4,00 \\
\hline 2. Memotivasi siswa untuk mengikuti pelajaran & & $\sqrt{ }$ & & 3,00 \\
\hline 3. Menyampaikan tujuan pembelajaran & $\sqrt{ }$ & & & 4,00 \\
\hline B. Kegiatan Inti & & & & \\
\hline 1. Menguasai bahan & $\sqrt{ }$ & & & 4,00 \\
\hline 2. Penyajian jelas & $\sqrt{ }$ & & & 4,00 \\
\hline $\begin{array}{l}\text { 3. Mempersiapkan materi pelajaran dengan rapi dan } \\
\text { sistematis }\end{array}$ & $\sqrt{ }$ & & & 4,00 \\
\hline $\begin{array}{l}\text { 4. Melaksanakan kegiatan pembelajaran yang sesuai } \\
\text { dengan pembelajaran dalam urutan dan arah yang } \\
\text { jelas }\end{array}$ & $\sqrt{ }$ & & & 4,00 \\
\hline 5. Upaya menertibkan siswa & & $\sqrt{ }$ & & 3,00 \\
\hline $\begin{array}{l}\text { 6. Memberikan kesempatan kepada siswa untuk } \\
\text { mengungkapkan pendapatnya }\end{array}$ & $\sqrt{ }$ & & & 4,00 \\
\hline $\begin{array}{l}\text { 7. Mengungkapkan pertanyaan dengan jelas dan } \\
\text { singkat }\end{array}$ & $\sqrt{ }$ & & & 4,00 \\
\hline 8. Merespon jawaban siswa & $\sqrt{ }$ & & & 4,00 \\
\hline 9. Memuji siswa yang berprestasi & & $\sqrt{ }$ & & 3,00 \\
\hline 10. Memberikan dan menilai hasil pelajaran siswa & $\sqrt{ }$ & & & 4,00 \\
\hline 11. Memotivasi siswa agar lebih giat belajar & & $\sqrt{ }$ & & 3,00 \\
\hline C. Kegiatan Penutup & & & & \\
\hline 1. Merangkum isi pelajaran & & $\sqrt{ }$ & & 3,00 \\
\hline 2. Memberi tugas & $\sqrt{ }$ & & & 4,00 \\
\hline D. Suasana Belajar & & & & \\
\hline 1. Siswa antusias & & $\sqrt{ }$ & & 3,00 \\
\hline 2. Guru antusias & $\sqrt{ }$ & & & 4,00 \\
\hline 3. Waktu sesuai alokasi & $\sqrt{ }$ & & & 4,00 \\
\hline 4. KBM sesuai dengan skenario RPP & & $\sqrt{ }$ & & 3,00 \\
\hline Jumlah & & & & 73 \\
\hline Rata-rata & & & & 3,6 \\
\hline Persentase rata-rata & & & & $91 \%$ \\
\hline
\end{tabular}


PeTeKa (Jurnal Penelitian Tindakan Kelas dan Pengembangan Pembelajaran)

Vol 1 No 3 Tahun 2018 Hal 192-201

Peneliti melakukan refleksi terhadap pelaksanaan siklus kedua, menganalisis serta membuat kesimpulan atas pelaksanaan pendekatan pembelajaran dan peningkatan hasil belajar siswa dalam pelajaran biologi. Setelah melewati siklus II ini melalui pertemuan pertama dan kedua, pelaksanaan pembelajaran dengan menerapkan model Project based learning sudah berhasil karena indikator keberhasilan pada penelitian ini telah tercapai dari siklus I ke siklus II hasil tes meningkat $21,88 \%$ dan hasil observasi pengelolaan pembelajaran biologi juga mengalami kemeningkatan sebesar $21 \%$. Dari data ini dapat disimpulkan bahwa penelitian tindakan kelas sudah berhasil dan mencapai indikator keberhasilan yang ditetapkan sehingga penelitian dihentikan sampai di siklus II.

Berdasarakan keberhasilan pada siklus II ini, telah terjadi peningkatan hasil belajar, aktivitas belajar dan kinerja guru sehingga penelitian ini berhenti di siklus II (akan dijelaskan kemudian pada pembahasan di halaman 65), karena menurut Suharsimi Arikunto (2006) penelitian tindakan kelas (PTK) dikatakan berhasil apabila telah memenuhi peningkatan hasil sesuai kriteria ketuntasan ideal (KKI) sebesar $75 \%$. Peninkatan kreativitas dapat dilihat pada gambar 1.

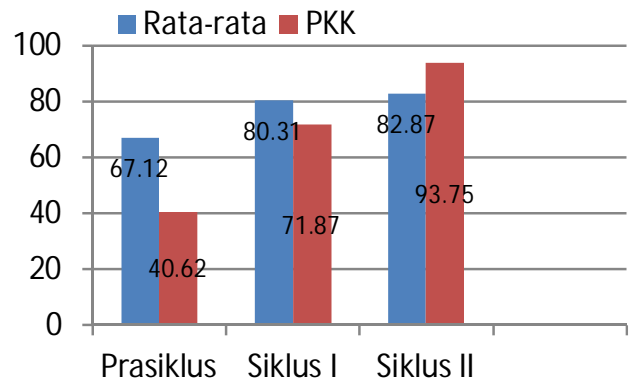

\section{Gambar 1: Peningkatan Hasil Tes Kreativitas Belajar}

Dari gambar 1, dapat kita lihat bahwa secara keseluruhan penerapan model pembelajaran Project Based Learning dapat meningkatkan kreativitas siswa dari prasiklus dengan persentase ketuntasan 67,12 menjadi $71,87 \%$ pada siklus I (meningkat $4,75 \%$ ) dan terus meningkat menjadi 93,75\% pada siklus II (meningkatan $21,88 \%$ ). Jika kita lihat kondisi real kelas melalui indikator kreativitas yang dinilai maka diperoleh hasil tes dari siklus I ke siklus II sebagaimana terlihat pada tabel 7 .

Fleksibilitas merupakan kemampuan siswa dalam menghasilkan gagasan, jawaban atau pertanyaan yang bervariasi. Dari hasil penelitian menunjukkan bahwa siswa sudah mampu memberi jawaban maupun pertanyaan yang bervariasi meskipun tujuannya adalah sama. Hal ini dapat dilihat dari lembar jawaban siswa ketiika menjawab tes dengan jawaban yang bervariasi dari masing-masing siswa dan kebiasaan siswa pada siklus II dalam melihat suatu masalah dari sudut pandang yang berbeda-beda. Selain itu siswa juga sudah mampu mencari banyak alternative atau arah yang berbeda-beda dalam memecahkan masalah dari prasiklus ke siklus I terus meningkat sampai ke siklus II. 
Fitri Agustina Lubis. Upaya Meningkatkan Kreativitas Siswa Melalui ...

Tabel 7: Rekapitulasi Peningkatan Kreativitas Berdasarkan Indikator Penilaian

\begin{tabular}{clcccccc}
\hline No & $\begin{array}{l}\text { Indikator } \\
\text { Kreativitas }\end{array}$ & $\begin{array}{c}\text { Prasiklus } \\
(\boldsymbol{\%})\end{array}$ & $\begin{array}{c}\text { Siklus } \\
\mathbf{I}(\boldsymbol{\%})\end{array}$ & $\begin{array}{c}\text { Siklus II Peningkatan } \\
(\boldsymbol{\%})\end{array}$ & & & \\
\hline 1. & Fleksibilitas & 67,08 & 72.30 & 93,02 & 20.72 & $23.62 \%$ & Baik \\
2. & Originalitas & 67,91 & 71.15 & 92,92 & 21.77 & $24.82 \%$ & Baik \\
3. & Elaborasi & 71,11 & 71.60 & 95,15 & 23.55 & $26.85 \%$ & Baik \\
4. & Fluency & 59 & 72.26 & 93,91 & 21.65 & $24.68 \%$ & Baik \\
& Jumlah & 265,10 & 287.31 & 375 & 87.69 & $99 \%$ & \\
& Rata-rata & 66,27 & 71.87 & 93,75 & 21.88 & & \\
\hline
\end{tabular}

\section{Pembahasan}

Slameto (2003) menjelaskan

bahwa pengertian kreativitas

berhubungan dengan penemuan sesuatu, mengenai hal yang menghasilkan sesuatu yang baru dengan menggunakan sesuatu yang telah ada. Sesuatu yang baru itu mungkin berupa perbuatan atau tingkah laku, bangunan, dan lain-lain. Teori ini lebih cenderung menegaskan bahwa kreativitas baru akan muncul jika ada sesuatu yang telah ada sebelumnya. Artinya, kreativitas hanya berupa pengembangan dari yang sudah ada, maka setelah melakukan analisa data terhadap tes kreativitas diperoleh data peningkatan.

Originalitas adalah kreativitas siswa dalam melahirkan ungkapan yang baru dan unik. Dari hasil penelitian menunjukkan bahwa siswa sudah mampu memikirkan cara yang tidak lazim untuk mengungkapkan sesuatu istiliah atau dalam menjelaskan sesuatu. Hal ini dapat dibuktikan dengan argument-argumen yang disampaiakan siswa dalam menjawab soal tes dimana siswa lebih senang menjelaskan dengan bahasa dan istilah mereka sendiri. Selain itu, tampaknya siswajuga mempunyai kemauan keras untuk menyelesaikan soal-soal biologi. Meskipun jawabannya masih kurang tetap akantetapi mereka telah berusaha untuk tidak mengosongkan jawaban.

$$
\text { Elaborasi merupakan }
$$
kemampuan siswa dalam menanggapi pertanyaan-pertanyaan secara bergairah, aktif dan bersemangat dalam menyelesaikan soal tes. Dari hasil penelitian, elaborasi merupakan nilai unggul dengan skor paling tinggi yang diperoleh siswa jika dibandingkan dengan indikator yang lain baik itu pada prasiklus, siklus I dan siklus II. Hal ini dapat dibuktikan dari hasil tes dimana siswa terlihat lebih senang dalam mencari cara atau metode yang praktis dalam menjawab pertanyaan.

Fluency adalah kreativitas siswa dalam mencetuskan banyak gagasan, jawaban, penyelesaian masalah ataup pertanyaan. Dari hasil penelitian, fluency berada di urutan terendah pada saat prasiklus namun bias menyeimbangi indikator yang lain setelah melewati pembelajaran siklus I. Selain itu kemandirian dalam belajar biologi siswa serta sikap agresip dalm bertanya juga menunjukkan bahwa siswa memiliki fluency yang baik setelah berada di siklus II. Secara keseluruhan, persentase dari masingmasing indikator kreativitas ini menunjukkan porsi hamper sama dari prasiklus ke siklus I maupun dari siklus I ke siklus II dan tidak terdapat perbedaan yang signifikan diantara indikator-indikator tersebut.

Pengelolaan Pembelajaran merupakan suatu kompetensi atau keahlian yang harus dimiliki oleh guru dalam mengatur proses belajar mengajar demi tercapainya tujuan pembelajaran. Guru memiliki peran yang sangat penting dalam menentukan kuantitas 
PeTeKa (Jurnal Penelitian Tindakan Kelas dan Pengembangan Pembelajaran)

Vol 1 No 3 Tahun 2018 Hal 192-201

dan kualitas pengajaran yang dilakukannya. Oleh karena itu, guru harus memikirkan dan membuat perencanaan dalam meningkatkan kesempatan belajar siswa dan memperbaiki kualitas mengajarnya. Pengelolaan pembelajaran merupakan kemampuan guru dalam proses belajar baik itu kemampuan untuk merencanakan, melaksanakan, dan mengevaluasi kegiata pembelajaran.

\section{SIMPULAN}

$\begin{array}{llr}\quad \text { Dalam } & \begin{array}{c}\text { penelitian ini, } \\ \text { pelaksanaan } \\ \text { menerapkan }\end{array} & \begin{array}{r}\text { inaran dengan } \\ \text { model pembelajaran }\end{array}\end{array}$

Project based learning pada materi pokok pencemaran lingkungan dalam penelitian ini berjalan dengan baik dan mengalami peningkatan selama pelaksanaan pembelajaran. Hal ini dibuktikan dengan perolehan nilai ratarata total aktivitas guru dalam mengelola pembelajaran pada siklus I masih sebesar 2,8 dengan persentase $70 \%$ atau berada pada kategori cukup. Pada siklus II nilai rata-rata total yang diperoleh meningkat menjadi 3,3 dengan persentase $91 \%$ atau berada pada kategori sangat baik. Untuk hasil yang lebih jelas mengenai peningkatan kadar aktivitas guru dalam mengelola pembelajaran dari siklus I ke siklus II.

\section{DAFTAR PUSTAKA}

Arikunto, S. 2006. Prosedur Penelitian : Suatu Pendekatan Praktik, Edisi Revisi VI, Jakarta: PT Rineka Cipta.

Fatmawati, B. 2011. Pembelajaran Berbasis Proyek Untuk Meningkatkan Keterampilan Berfikir Kreatif Mahasiswa. Jurnal Pengajaran MIPA 16(2).

Hakim, N. 2015. Penerapan ProjectBased Learning Dipadu Group Investigetion Untuk Meningkatkan Motivasi, dan Hasil Belajar Mahasiswa Pendidikan Biologi Universitas Muhammadiyah Malang. Jurnal BIODIK 1(1).

Insyasiska, D., Siti Z., dan Herawati S. 2015. Pengaruh Project Based Learning Terhadap Motivasi Belajar, Kreativitas, Kemampuan Berpikir Kritis dan Kemampuan Kognitif Siswa Pada Pembelajaran Biologi. Jurnal Pendidikan Biologi 7(1).

Sani, R. dan Sudiran. 2012. Penelitian Tindakan Kelas. Medan Citapustaka.

Slameto. 2003. Belajar dan Faktor yang Mempengaruhinya. Jakarta: Rineka Cipta. 